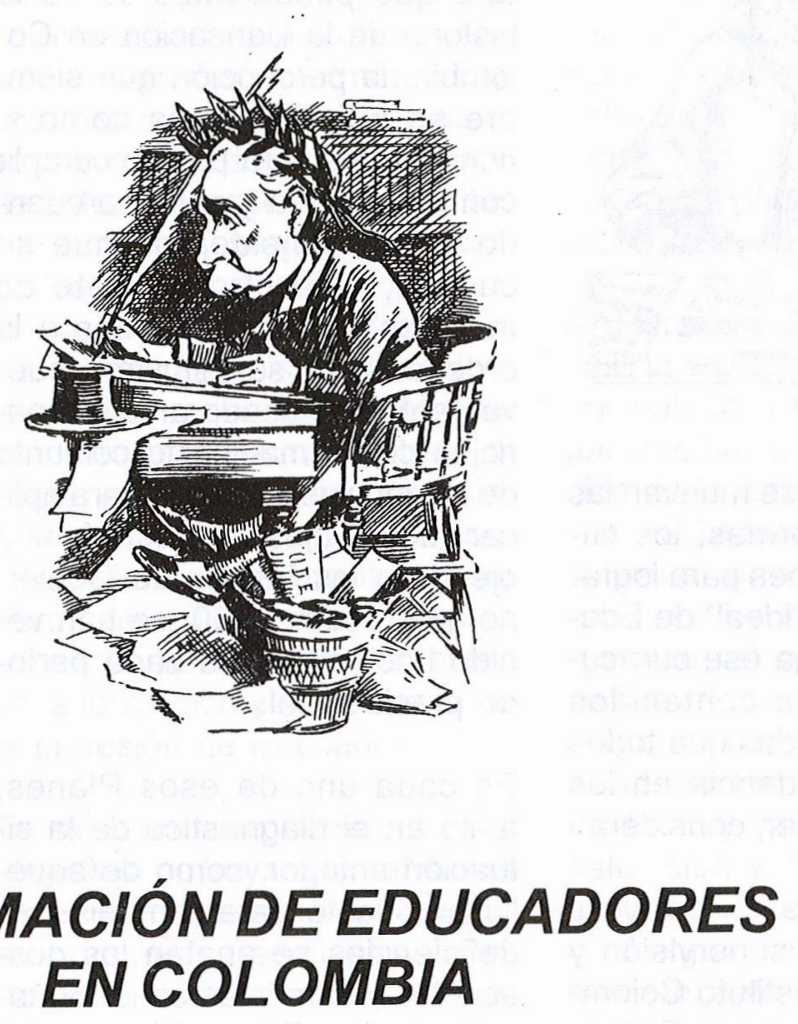

\title{
LA FORMACIÓN DE EDUCADORES EN COLOMBIA
}

\author{
Libia Stella Niño Zafra \\ Profesora Titular Universidad Pedagógica Nacional \\ Rafael Díaz Borbón \\ Profesor Universidad Distrital
}

\section{Introducción}

La formación de Docentes, como un pensamiento surcado de preocupaciones, necesidades, politicas, reformas curriculares y administrativas, normas y exigencias perentorias, parece ser una constante del Sistema Escolar a través de distintos poderes y gobiernos, desde hace mucho tiempo. Por diversos motivos, y alegando las más diversas razones, siempre se ha hecho pública la crítica acerca de un sinnúmero de requisitos que supuestamente debe cumplir un programa de formación, de condiciones, de orden personal hasta social, familiar, político, pedagógico y ético, de desempeño pedagógico y de enseñanza, hasta cuanto debe hacer o no dentro de la institución educativa y fuera de ella. Desde interpretar los resultados de unos exámenes practicados a los estudiantes como muestra eficiente de la calidad de la preparación y la docencia de un Educador, hasta considerar la crisis del país reflejo directo de la calidad de la enseñanza que se imparte.

Por eso, quizá, ante esa especie de debate y mirada públicos (en cuyo centro está la clase de Educadores requeridos, el tipo de formación a recibir, en dónde, qué tipo de avituallamiento científico, artístico, filosófico, pedagógico debe proveer esa formación, para impartir qué clase de educación y cuáles finalidades, durante unos determinados pe- 


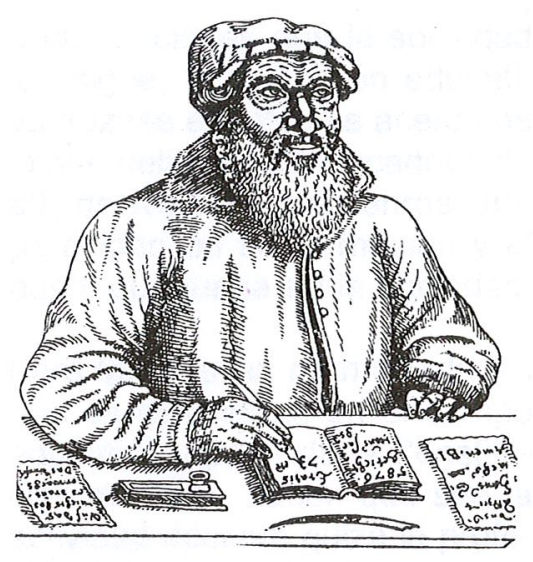

ríodos de tiempo), se mueven las decisiones, las normas, los currículos y condiciones para lograr obtener y dotar el "ideal" de Educador que satisfaga ese currículo, no siempre de contenidos iguales, de demandas que todos aquellos, con incidencia en los escenarios de poder, consideran se deben cumplir.

Las entidades de supervisión y control (como el Instituto Colombiano de Fomento de la Educación Superior, ICFES, las Universidades Oficiales y Privadas, mediante sus Facultades de Educación, las Escuelas Normales formadoras de Maestros para la Educación Primaria), los mismos aparatos legislativos, confeccionadores de leyes, las Secretarías de Educación, Distritales, Departamentales y Municipales, con interés no siempre eficaz y acudiendo a distintos mecanismos y aplicaciones, han intentado, con éxito o no, satisfacer el conjunto de exigencias precisadas por cada urgencia conformada desde distintos puntos de vista, contemporáneamente, tanto internamente dentro de los escenarios del país como fuera de él, desde centros de poder inter- nacional ligados a políticas de orden económico. Frente a todos estos "esfuerzos", según una lectura que pueda hacerse de la historia de la Educación en Colombia, la percepción que siempre se manifiesta, es como si nunca se hubiera podido cumplir con el esfuerzo y si como cuando se ha considerado que se cumple, ante otro paquete de medidas, de acatamientos a lo ordenado, ya se estuviera nuevamente desfasado ante la aparición de un manifiesto conjunto de exigencias y críticas para aplicar nuevos ajustes. Bastaría una ojeada a los Planes de Gobierno que, desde 1960 , se han venido haciendo para cada período presidencial.

En cada uno de esos Planes, tanto en el diagnóstico de la situación anterior, como de aquello propuesto para remediar las deficiencias se anotan los desaciertos y carencias en la formación de los Educadores y del ideal de calidad de Educación no alcanzado y, luego, páginas adelante, se formulan las soluciones a llevar a cabo por el gobierno de turno. Esto es, entonces ya, un lugar común en estos Planes.

¿Dónde radican, entonces, los desfases? ¿En la falta de precisión y veracidad de los juicios, que como un conjunto de exigencias se formulan? ¿En los mecanismos, reformas y ajustes que se llevan a cabo durante los procesos de formación? En la cantidad, calidad, capacidad de acertar en los programas curriculares? ¿En la condición, capacidad y exigencias académicas y profesionales de quienes se forman en las instituciones forma- doras? ¿En el grado de compromiso, condiciones de trabajo, reconocimiento laboral y social, para llevar a cabo la ardua y compleja labor de educar? ¿En la sociedad en su conjunto, en las fuerzas de poder intervinientes, en los modelos sociales y económicos, en las "exigencias" de parte para ajustar los planes de formación, los modelos de maestro, a políticas macro-económicas de demandas exógenas, no identificadas exactamente con las exigencias naturales internas? ¿En la evaluación misma del ser humano, del conocimiento en general, de la Pedagogía y de la Educación, de la Cultura del país y del mundo? ¿Ante complejas y tan amplias expectativas, ¿cómo acertar, cómo dar en el punto sustantivo a cada tanto? Será, acaso, que, muchas de las veces, se demanda de las instituciones formadoras, de la Universidad y de los mismos Maestros tareas y metas que no corresponden, por la misma naturaleza de éstas y de éstos, a su organización y prácticas constitutivas, aunque sea, apenas lógico, cambien progresivamente de modo normal -no a sobresaltos, a mandobles de políticas de Estadocon el fluir cambiante de la sociedad, de los saberes, de la evolución cultural de los tiempos. Sin embargo, ni la Educación ni los Educadores, pueden ser exigidos de convertirse en panacea para remediar todos los males sociales, todas las carencias, debilidades y anhelos individuales, así ésta pueda ayudar, predisponer para construir las soluciones, su acción, tiene límites.

Cada etapa y momento, entonces, de la Educación en Colom- 
bia, de acuerdo con el papel que la sociedad le ha otorgado; no sólo ha dejado de hacer o hacer en cumplimiento a unos requerimientos en forma de necesidades y/o fines, o de escuetas exigencias, sino que ha señalado la concepción, formación y prácticas que deben definir lo que es el Educador y ha demandado su cumplimiento a través de la docencia en las instituciones educativas. En los años 90 del siglo $X X$, esas exigencias, ese debate público sobre la Educación, sobre el papel del Educador y el tipo de formación a recibir para una Educación, centrada en lo entendido como calidad, tiene un énfasis muy grande, traducido en expectativas, de cara a un nuevo siglo, igualmente, muy grandes. Esto, una vez más, pareciera ser parejo a cuanto del país, en este mismo advenimiento, espera, a través de políticas y programas de gobierno y frente a exigencias de sucesivos cambios de rumbo del ordenamiento económico y tecnológico internacionales.

Por ejemplo, bajo la égida de la denominada globalización, que decididamente por diversos medios, presiona sobre las formas de organización y conducción del país para situarlo dentro de ese ordenamiento y donde a la Educación se la exalta como un campo determinante desde un protagonismo esperado del conocimiento para posicionarse 0 , al menos, mantenerse fronteras adentro de ese reordenamiento globalizador, dinamizador del Sistema Escolar, a través de su praxis profesional en las instituciones educativas, el papel del Educador con miras a las metas sociales esperadas, se lo valora como definitivo. Esto explicaría, en buena parte, el por qué de una preocupación ampliamente compartida, trasladada a decisiones políticas y normas jurídicas, con miras a reforzar todo el ámbito de la Educación y, dentro de éste, ese aspecto crucial, las instituciones y programas encargados de la formación docente, los requerimientos formativos necesarios a la misma Profesión, la calidad requerida en el desempeño profesional. Como si desde el mismo Estado se hiciera evidente un celo acucioso, una voluntad de mantener de cerca un control bien estricto sobre los asuntos intervinientes en la formación y desempeño de la profesión de Educador.

Tal vez, en este tiempo de los años 90 s, no hay reglamentación más severa para profesión alguna, a como se encuentra sobre las unidades académicas dedicadas a la preparación de maestros y sobre las condiciones para su formación, su desempeño y los resultados esperados de su ejercicio en el sector educativo. Estos items se han vuelto asunto estratégico de alta hermenéutica de gobierno. Otra cosa pudiera significar la voluntad política de llevarla a la práctica en las realidades educativas, en la forma a como, ya dentro del terreno de las vivencias programáticas, pueda tenerse presente. En cómo, en medio de las contradicciones y complejidades políticas, institucionales, humanas, académicas, de enseñanza y aprendizaje, en el mundo de la vida de cada uno de sus co-protagonistas, pueda ser la homogeneidad, heterogeneidad $\mathrm{y} / \mathrm{o}$ disparidad de resultados, al momento de evaluar los propósitos y las soluciones provistas a las necesidades planteadas. Las cuantificaciones a la manera de balances, en el terreno de lo educativo, de lo humano, por impactantes sus cifras, constituyen apenas puntos de referencia, indicios, simplemente.

A diferencia de las demás épocas, la Constitución de 1991, al dar cabida a la concepción, organización, dirección y evaluación de la Educación como política de Estado, emitió criterios sobre la formación de los Educadores. En su artículo 68, por ejemplo, el parágrafo tercero, señala: "La enseñanza estará a cargo de personas de reconocida idoneidad ética y pedagógica. La Ley garantiza la profesionalización y dignificación de la actividad docente". En Constitución alguna anterior, hubo pronunciamiento semejante.

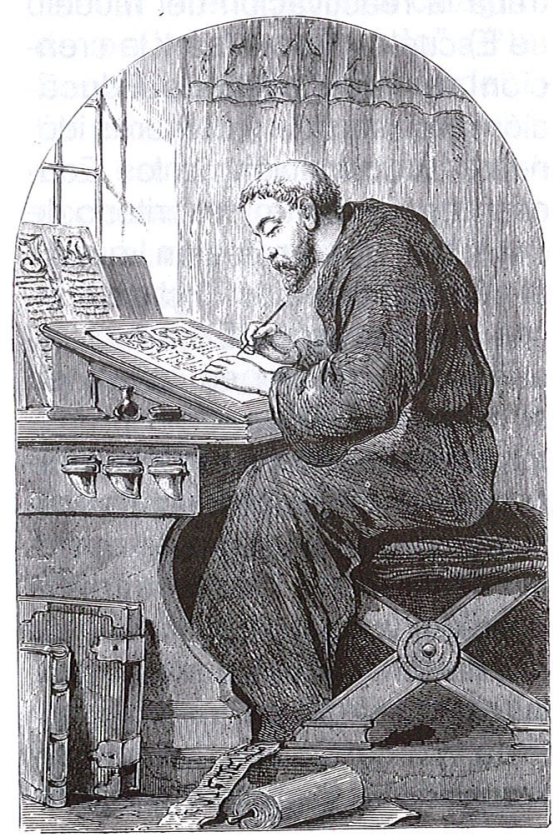




\section{Formación Docente y Normatividad}

Sobre una ya larga tradición en la historia de la Educación Colombiana, la formación de los Educadores, desde la creación de las llamadas Escuelas Normales, Rurales y Superiores, y desde la puesta en marcha de las Facultades de Educación, en las ciudades de Tunja y Bogotá, (la primera una Capital de Provincia y la segunda la Capital de la República, en el centro del país en la región andina), por los años de 1930, en la denominada "República Liberal", después de una prolongada hegemonía del Partido Conservador, finalmente se hizo impostergable la urgencia de dar a los Maestros una formación profesional, en planteles especialmente concebidos para tal fin.

A mediados de la década de 1920, se había traído al país la Segunda Misión Alemana, dentro de cuyas propuestas de reforma de la Educación se encontraba la reactivación del modelo de Escuelas Normales y la creación de Facultades de Educación, provistas de profesores idóneos. La formación de los Educadores, ya dentro del criterio de constituir una profesión, quedó al cuidado de estas organizaciones educativas: La Escuela Normal, como plantel educativo en sí mismo, dedicado a la preparación de Maestros para la Educación Primaria y, en muchas ocasiones, por la carencia de opciones diferentes, de Secundaria también, y de las Facultades de Educación, unidades administrativas y académicas pertenecientes a la organización de una Universidad. Más que por fuerza de

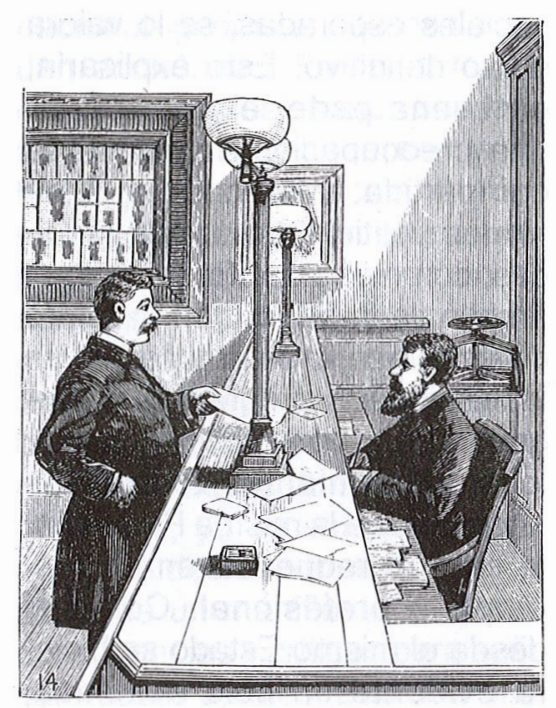

ley, esta ha sido una tradición institucional mantenida hasta hoy. Sin embargo, en las nuevas disposiciones de esta década en mención, por momentos se ha dejado traslucir, en ciertas expresas ambigüedades semánticas, la intención de abrir la puerta a otras "unidades académicas". Por los requisitos exigidos para que alguna "unidad académica", distinta a la organización que posee la existencia de una Facultad de Educación, no será, por ahora, probable una iniciativa así.

Con base en los apoyos brindados por la Constitución Política y una mentalidad casi unánime del carácter profesional que debe poseer el ejercicio de la docencia, a cualquier nivel del Sistema Escolar, tanto como del avance del conocimiento, del desarrollo de la sociedad y de los progresos de la Pedagogía, de otras demandas ianto internas como externas al posicionamiento del país, se emite la Ley 30 de 1992 , o Ley de la Educación Superior sustitutiva del Decreto 080 de 1980. Si bien, no abunda en establecimiento de lineamientos sobre estos tópicos, como sí debió hacerlo, al proponer en el artículo 25 el título de "Licenciado" para las Carreras de Educación, a diferencia de los otros títulos otorgados por las instituciones universitarias, reafirmó la formación de Educadores una tarea primordial de la Educación Superior. Para quienes proclaman la no necesidad de la formación pedagógica en el currículo del Licenciado, sino solamente el dominio de una asignatura a enseñar dentro de una cierta visión tecnológico-instrumental del conocimiento, allí, en el mismo artículo, en el segundo apartado del parágrafo 1 , se propuso la desaparición de las Facultades de Educación, acudiendo al procedimiento de asimilar la función y sus programas de estas al resto de unidades académicas (físico, químico, matemático, etc.), liberándose del aprendizaje de la Pedagogía.

La Ley 30 de 1992, en la pluralidad de fuerzas intervinientes en la confección de cada uno de sus artículos, pretendió encausar definitivamente todo este nivel del Sistema Escolar. Con la división introducida, de Educación Universitaria Oficial o Pública y Educación Privada, la segunda salió ampliamente ventajosa. El Artículo 69 de la Constitución Política sobre autonomía universitaria, en la Ley 30 , pasó a ser una autorización incontrolada de libertad de empresa, con repercusiones inmediatas. Un mercado desenfrenado de proliferación de unidades formadoras de Docentes y feria de títulos de Licen- 
ciados, sin lleno de requisitos apenas elementales y baja calidad de educación. Según el documento "Hacia un Sistema Nacional de Formación Docente" de 1998, del Ministerio de Educación Nacional, existían 135 Normales en proceso de Acreditación para transformarse en Normales Superiores, 617 programas de nivel de licenciaturas, 282 especializaciones, 40 maestrías y dos doctorados (M.E.N., 1998: 41). Como consecuencia, sobrevino una enorme preocupación e inestabilidad para las Facultades que tradicionalmente venían dedicadas a las labores de su competencia.

En 1994, se expide la Ley 115 o Ley General de Educación, preferencialmente para los niveles de Educación Preescolar, Básica Primaria, Básica Secundaria y Media, en donde se dedica el Capítulo II a la formación de Educadores. El Artículo 109, de este Capítulo, fija como fines "...formar un Educador de la más alta calidad científica y ética, b) desarrollar la teoría y práctica pedagógica como parte fundamental del saber del educador, c) fortalecer la investigación en el campo pedagógico y el saber específico y d) preparar Educadores a nivel de pregrado y de postgrado para los diferentes niveles y formas de prestación del servicio educativo" (M.E.N., 1994:65). Por igual, esta Ley mantiene la responsabilidad de la formación y actualización de los Educadores, del nivel de pregrado y postgrado, en las Universidades e instituciones de Educación Superior, en su Artículo 112. (M.E.N., 1994: 65). Se establece, en el mismo Artículo
112, en el Parágrafo, que las Escuelas Normales reformadas, con dos años más de educación después del grado once, podrán formar Educadores para el nivel Preescolar y el ciclo de Educación Básica Primaria. En Diciembre 31 de 1994, el Decreto 2903, con fundamento en el Ley 115 , contiene los procedimientos para la reestructuración de estas Escuelas, siempre y cuando cuenten con la asesoría de una Universidad.

Con relación a la profesionalización y actualización de Docentes, en 1996, se expide el Decreto 709 , por el cual se "...establece el reglamento general para el desarrollo de Programas de Formación de educadores y se crean condiciones para su mejoramiento". (M.E.N., 1997: 392). Se ocupa de la estructuración de los programas de formación, atendiendo a cuatro campos: formación pedagógica, disciplinaria específica, científica investigativa y deontológica y en valores

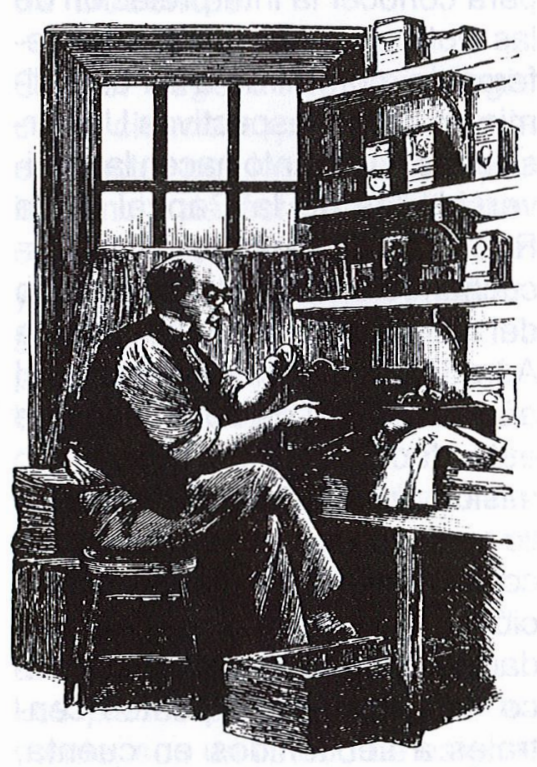

humanos. Enfatiza el papel de las Facultades de Educación y de los Departamentos a través de las Secretarías de Educación, Departamentales y Municipales, en el perfeccionamiento y profesionalización de los Docentes en ejercicio.

En este año 1996, a instancias del Presidente de la República, se conformó "un grupo de personas destacadas en las distintas ramas del saber, llamado $\mathrm{Mi}$ sión de Ciencia, Educación y Desarrollo", quienes elaboraron el documento "Al filo de la Oportunidad". Uno de sus apartados centrales tiene que ver con la "dignificación de la Profesión Docente", recomendando la "renovación continuada de la preparación de los docentes" y el mejoramiento sustancial de las remuneraciones.

Durante este mismo tiempo, por disposición de la Ley 115, se divulga el Plan Decenal de Educación 1996-2005, con el fin de "elevar la educación a categoría de política de Estado" (Plan Decenal, 1996:1). Para adelantar este plan se proponen objetivos, estrategias y programas de acciones, entre los que se destaca el mejoramiento de la calidad de la Educación a través de la cualificación de los Docentes, mediante la creación de un Sistema Nacional de Formación de Educadores, donde estarían las Escuelas Normales Superiores y las Universidades o instituciones universitarias. Estaría encaminado a unificación de políticas, normas, esfuerzos dispersos, en un trabajo de conjunto de todas las instituciones encargadas de la formación de Docentes, aunque 
su formulación, por no estar avalado en un Decreto o Ley, carece de obligatoriedad y queda a disposición de la voluntad política su desarrollo y su conversión en norma jurídica.

Para orientar y mantener el mejoramiento continuo de la tarea de formación docente, tanto en Normales como en Facultades de Educación, la Ley 115 había establecido la figura de Acreditación Previa. Los Decretos 3012 de 1997 y 272 de 1998, para Escuelas Normales y Facultades de Educación respectivamente, buscan desarrollarla y ser una guía para su puesta en práctica, mediante el lleno de 26 requisitos de obligatorio cumplimiento, según lo consignado en el documento "Criterios y Procedimientos para la Acreditación Previa de los Programas Académicos de Pregrado y Epecialización en Educación", presentado por el Consejo Nacional de Acreditación, (C.N.A.).

Escuelas Normales Superiores y Facultades se dedican, antes del año 2000, a reunir las condiciones para esta Acreditación, fecha en la cual vence el plazo acordado por la Ley. Las Facultades de Educación, se ayudan en esta tarea del documento mencionado, del C.N.A. Este organismo asesor, fue creado por la Ley 30 para regular y controlar la existencia y funcionamiento de las Universidades y de las Facultades de Educación, con el fin de garantizar niveles de calidad en la formación de Educadores y evitar la proliferación incontrolada de éstas y de Maestros sin suficiente preparación profesional. La tarea de vigilan- cia y evaluación del C.N.A., sirve para que el Consejo de Educación Superior, CESU, presidido por el Ministro de Educación, conceda o niegue la aprobación previa y después definitiva a estas unidades académicas y sus programas de Licenciatura. Aunque la Ley 30 dejó voluntaria la Acreditación de las Universidades, en lo concerniente con las Facultades de Educación y las Licenciaturas, mediante los Decretos antes citados, el 709 y 272 , convirtió para éstas en obligatoria la Acreditación, estableciendo un paso primero consistente en la Acreditación Previa. En consecuencia, para un programa si llega al año 2000, sin haberla obtenido no podría seguir funcionando; si habiéndola solicitado, no se le hubiere concedido, contará con un año más para reintentar alcanzarla después de lo cual sobrevendría el cierre.

La Asociación Nacional de Facultades de Educación torna suya la tarea y promueve encuentros para conocer la interpretación de las normas y fijar puntos de referencia, con miras a su cumplimiento en las respectivas Universidades. Otro tanto hacen las Universidades de la Capital de la República de carácter Oficial, escuchando una de otra, el estado del arte para la obtención de esta Acreditación Previa, durante el año de 1998. Los 26 criterios de este documento se refieren a: misión, visión, plan de desarrollo y núcleo de saber pedagógi$c o$, demarcadores de la orientación organizativa y curricular a dar en cada programa académico. Los núcleos, o puntos centrales a ser tenidos en cuenta, hablan de la "educabilidad del ser humano..." ..."la enseñabilidad de las disciplinas y los saberes producidos por la humanidad..." ... "la dimensión deontológica de la profesión docente". Otros apuntan a aspectos organizativos, académicos, administrativos institucionales como complemento de lo curricular.

Como ya fue anotado en otra parte, estas últimas normas, con la Acreditación Previa Obligatoria, fueron una salida de emergencia del Gobierno de turno, ante la proliferación desmedida de. Facultades de Educación con programas de pregrado, magíster, doctorado, especializaciones y diplomas de la más variada índole, en una interpretación de la autonomía universitaria dominada por el afán de lucro, sobre todo, de un sector importante de la Educación Privada. Estas normas, entonces persiguen poner freno y ejercer un control permanentes.

En un país, como Colombia, donde se dictan normas para todo. las disposiciones legales emitidas durante estos años, sin lugar a duda, son una realidad, pero una realidad jurídica, que indica unos parámetros obligatorios para orientar y regular la acción. Ante una situación de anomalía, como la que se venía generando, Universidades Privadas, a cambio de altos precios de matrícula, estaban entregando títulos de Licenciado en tres y cuatro bimestres de estudio. Se imponía entonces una legislación severa. Pero no significa esto, de una parte, que fuera esta normatividad, ni la que fundara o regulara, a partir de ella, 


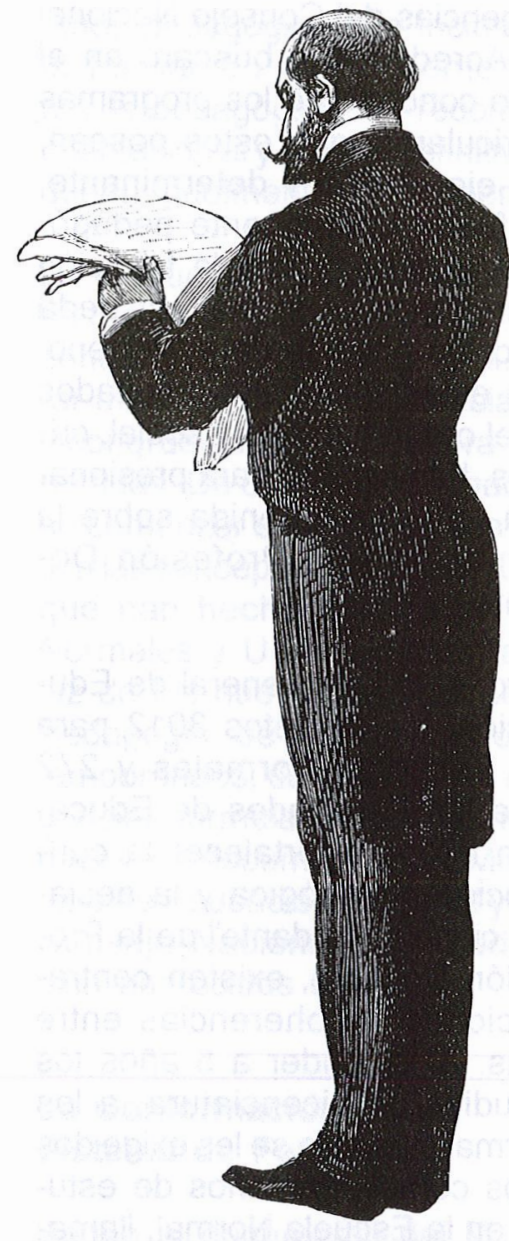

las Facultades de Educación y la preparación de Licenciados, cuando por una tradición de muchos años atrás, ya existía una realidad educativa y mediante otras normas se había intentado regular la Educación Universitaria. Estas normas llegan ahora a coadyuvar a la regulación de una realidad existente, fijando unos criterios de exigencia perentoria en su cumplimiento. De otra parte, la existencia de estas normas como nuevas, como realidades jurídicas, no significa cambios de rumbo, de por sí, en las prácticas educativas. Mientras estas no se asuman a plenitud por quienes deben apropiarse de sus contenidos convirtiéndolas en decisiones políticas, administrativas y académicas que a su vez, introduzcan replanteamientos y cambios administrativos, académicos, curriculares, de recursos de toda índole, de metodologías, mentalidades, en las Facultades de Educación y de las Universidades y también de las Escuelas Normales. Cuáles sean los cambios y los resultados de todo lo esperado con estas nuevas disposiciones, cuando apenas inician los procesos y ajustes, no compete aquí especular. Aunque se vive en un país donde la proliferación de leyes hace imposible a alguien -por más enterado- conocerlas todas, también se sabe que, según un inmemorial vicio, por un lado, va la ley y, por otro, la realidad y, pocas, muy pocas ocasiones entroncan una con la otra, juntas. Es de esperarse, en los días por venir, que esto no suceda así..

\section{La Orientación Pedagógicaen las Instituciones Formadoras de Docentes}

Con el auge de la Psicología como ciencia experimental de la conducta, por los años 70 s y la influencia de ésta en la Educación, a través de la investigación y la teoría curricular, la tecnología educativa y el traslado de las prácticas administrativas de la fábrica a la escuela, la orientación de los enfoques psicológicos para las instituciones educativas ha priorizado el logro de unos objetivos instrumentales, encaminados a la preparación de unas habilidades instrumentales. Los planes de estudio, generalmente, son un listado de asigna- turas aisladas, sin vínculos articulatorios o definitorios de procesos educativos más profundos.

La concepción pedagógica de estos currículos, por lo común, no ha facilitado la puesta colectiva de experiencias y en las $\mathrm{Fa}$ cultades de Educación y unidades formadoras de docentes persiste la "ausencia de debate sobre enfoques y modelos pedagógicos en general y de formación de educadores en particular..." (CNA, 1998:7). La visión de la Profesión Docente está limitada a unos esquemas operativos derivados del estudio de las disciplinas por separado: Psicología, Sociología, Antropología, Filosofía, Pedagogía, etc., estudiadas en forma disciplinar, sin la suficiente claridad y comprensión de la complejidad de la problemática educativa, dejando a la $\mathrm{Pe}$ dagogía sin objeto ni relación con esas ciencias.

Además de ese enfoque tecnológico predominante en el diseño curricular, ha persistido la hegemonía de lo disciplinar sobre lo pedagógico. El estudio del saber pedagógico, ha de constituirse así el eje de identidad profesional y la base para el análisis epistemológico del conocimiento destinado a los procesos de enseñanza-aprendizaje, de formación y, los aspectos igualmente específicos y esenciales. El currículo y la evaluación, padecen de la subestimación y desarticulación de un errado enfoque de lo pedagógico y de sus alcances en la constitución de la identidad profesional; del modo de abordar pedagógicamente el conocimiento y su proyección a 
través de la práxis docente y la recepción, asimilación y transformación, por parte del estudiante.

El enfoque, y cierta mentalidad acrítica de preparar para el hacer y formular soluciones, sustentado en una razón instrumental, todavía perpetuado en la misma organización de los planes de estudio y administración de ellos, incluso, en su enseñanza a través de las asignaturas de clase, reducen la Pedagogía a la didáctica, la ubican en uno o algunos semestres como materia ancilar o, simplemente, la excluyen. Estas mentalidades la consideran, de cualquier modo, innecesaria, inútil. Los esfuerzos de muchos docentes por posicionar a la Pedagogía en los programas como la ciencia fundante de la Profesión Docente, así como de la importancia, dentro de un componente pedagógico básico, de la Psicología, la Ética, las Competencias Comunicativas, la Estética (de una formación integral), chocan con inamovilidades programáticas en cada semestre académico y con quienes deciden las políticas y confeccionan los programas, aparte de otros aspectos y contextos igualmente nocivos.

El bajo reconocimiento social y el exiguo status salarial de la Profesión Docente, incide, por demás, en la identidad del Maestro, en su formación y desempeño como un contexto próximo, afecta definitivamente a los centros de formación. Por diversos factores, que escapan al propósito de este trabajo, una parte influyente de la sociedad no tiene un buen miramiento de la Pro- fesión Docente, sobre todo, frente a otras profesiones y a la remuneración que perciben por su trabajo. El salario de un Maestro no corresponde, ni a su formación ni al cubrimiento de sus necesidades personales y familiares y ha venido afectando, desde siempre, la calidad de su preparación permanente y la calidad de su docencia.

Aquí cabe resaltar cómo, del mismo modo, las disposiciones legales más recientes sobre requisitos y formación de Docentes en unidades académicas aptas y las

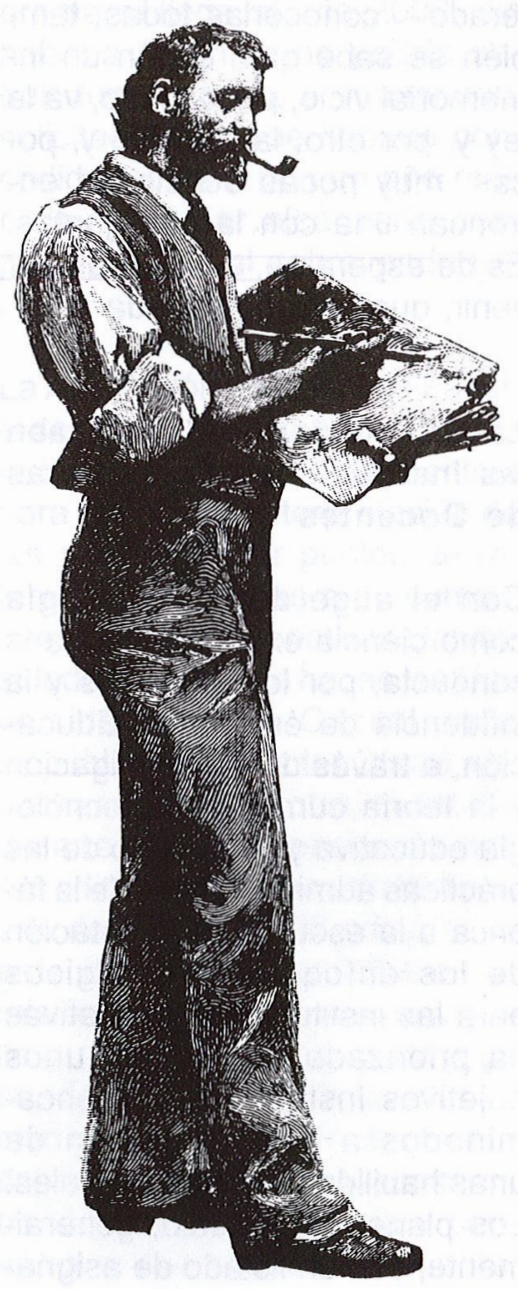

exigencias del Consejo Nacional de Acreditación, buscan, en el caso concreto de los programas curriculares, que estos posean, por eje central y determinante un fuerte componente pedagógico, que se rompa la tradición tecnológica o, al menos, ceda parcelas amplias de su terreno. Las estadísticas, los resultados en el orden humano y social, críticos, han servido para presionar una reflexión detenida sobre la formación y la Profesión Docente.

Pero, si la Ley General de Educación, los decretos 3012 para las Escuelas Normales y 272 para las Facultades de Educación intentan fortalecer la concepción pedagógica y la declaran ciencia "fundante" de la Profesión Docente, existen contradicciones, incoherencias entre ellas. Al extender a 5 años los estudios de Licenciatura, a los Normalistas solo se les exige dos años complementarios de estudio en la Escuela Normal, llamada ahora Superior, para el mismo tipo de enseñanza, la preescolar y la básica primaria, por ejemplo.

Como ya se ha expresado, queda por verse cómo será el replanteamiento al currículum, en qué consistirá la concepción pedagógica reestructurada, cómo han de ser las exigencias de las condiciones académicas elevadas a cinco años, cómo será la igualdad de reconocimientos con las demás profesiones. Aún no inician los dos años de demás para las Normales, la lucha por la dignificación de Maestros continúa vigente y si todo esto ha de ayudar a la construcción de un 
ethos pedagógico que incida en la formación del Docente, su práxis pedagógica, su reconocimiento social y laboral definitivos, queda igualmente en suspenso.

La propuesta de constitución de un Sistema de Formación de Docentes podría contribuír a superar muchas de las deficiencias e incongruencias hasta ahora denotadas. De conformarse, habría de comenzar exponiendo a la crítica las concepciones y currículos que han hecho carrera en las Normales y Universidades, a la luz de los nuevos aportes de la Pedagogía, de los saberes contemporáneos, de las mismas exigencias formuladas por las normas y los documentos del Ministerio de Educación Nacional y del Consejo Nacional de Acreditación aparecidos en 1998.

\section{La Conformación de un Sistema de Formación}

Según el documento del Ministerio de Educación, "Hacia un Sistema Nacional de Formación de Docentes", habría una voluntad política para implementar una organización que coordine la formación de los Educadores. No precisa planteamientos concretos sobre su estructura, principios y formas de organización para una conformación inmediata, sino se plasman simplemente unos indicadores generales. La promoción de un trabajo conjunto de las Universidades que administran programas de Formación de Docentes, bien pudiera tener el sentido de actividades preparatorias para tantear el terreno de la integración que podría iniciar el análisis conjunto del

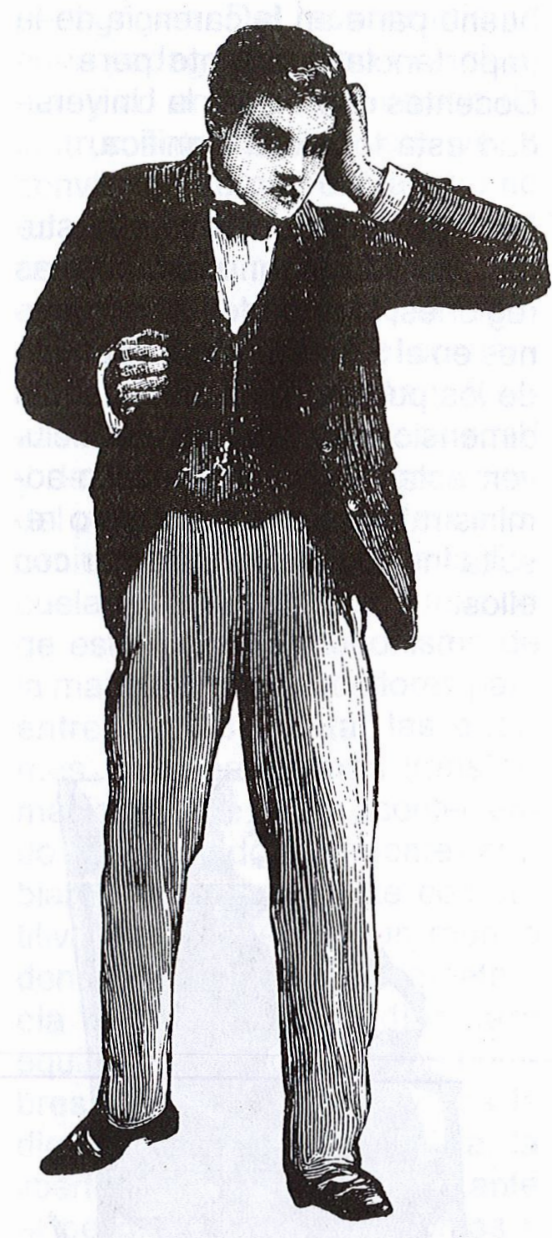

Sus fortalezas teóricas podrian estar orientadas a fortalecer de la identidad profesional y las relaciones teoría-práctica en lo educativo, "fundantes de la profesión". El trabajo pedagógico adelantado en las instituciones formadoras de docentes, de alguna manera, requeriría de la transición de la visión del Profesor como poseedor y transmisor de conocimientos, a la de un docente investigador, en permanentes indagación y sistematización de experiencias. La superación del modelo pedagógico tecnocrático, orientado por la psicología conductista del aprendizaje, a cambio de corrientes pedagógicas y curriculares más globalizadoras y comprensivas del fenómeno educativo, propiciadoras de un análisis crítico permanente y colectivo sobre las actividades de aprendizaje y los contenidos curriculares, contando con la autonomía del Educador y guardando inter-acción con los contextos, sería de gran importancia en una agenda de trabajo permanente de este sistema. La creación y apoyo a proyectos o programas de investigación hacia la construcción de respuestas a las problemáticas de la pedagogía, estaría también dentro de los items prioritarios de su plan de acción inmediato a través del currículo. En este sentido, la presentación de trabajos podría estar organizada alrededor de líneas y programas de investigación interinstitucionales en esa articulación curricular.

Esa posible estructuración del Sistema podría incluír el establecimiento de un paso continuado de una vez, para suprimir las barreras existentes desde los ni- 
veles de estudios de la Licenciatura hasta el Doctorado. El caso de las Escuelas Normales Superiores, sujeto a Convenios con las Facultades de Educación para la obtención de su Acreditación, por las desiguales condiciones del país, las Universidades pueden asistirlas en aquellas regiones distantes de ciudades donde no hay Facultades de Educación, mientras la Universidad consolida una presencia regular para formación de Licenciados. El ideal está en que todo Docente sea un profesional universitario de la Educación. En las ciudades con Facultades de Educación, estimular el ingreso a sus programas y las Escuelas Normales transformarse en planteles bien dotados de Educación Secundaria y Media.

Igualmente, un aspecto importante, para el Sistema y para la Acreditación Previa, apunta al reconocimiento de una categoría más alta en el Escalafón de los Maestros y el reconocimiento social y laboral del título de Licenciado, semejante al tratamiento dado a los profesionales de otras disciplinas.

Otro tiene que ver con estamento indispensable, para esta constitución: los egresados. La creación de agremiaciones, grupos, asociaciones, con propósitos de fortalecimiento de la comunidad académica y aporte de las mejores experiencias a los contenidos de la enseñanza, deviene relevante. Al tiempo, brinda de cerca oportunidades de actualización y profesionalización a quienes tanto lo necesitan. Su falta de organización y participación obervada hasta ahora, radica en buena parte en la carencia de la importancia que tanto para los Docentes como para la Universidad esta fortaleza significa.

Finalmente, la discusión y estudio sobre la organización de las regiones, localidades e instituciones en el Sistema augura ser uno de los puntos complejos, por las dimensiones y factores que incluyen estas divisiones político-administrativas en el país, pero resulta indispensable el contar con ellos.

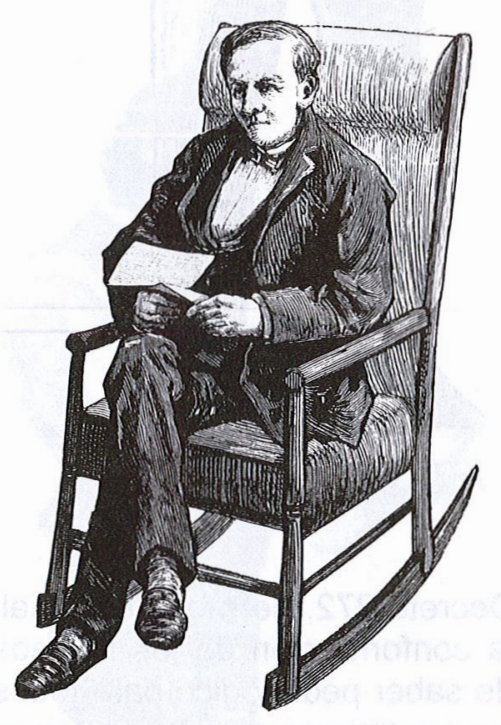

\section{Algunas Reflexiones Finales}

En los diez años considerados aquí, durante la década de los noventa, la formación de Docentes y la cualificación de su ejercicio en Colombia, corresponden a un período de más intensa de preocupación y reflexión crítica con la decisión de precisar y acertar, rectificar rumbos y provocar cambios significativos. A partir de 1991, con la promuigación de la nueva Constitución Política, se empieza a mencionar con frecuencia al Maestro para reconocer su valía pero, al mismo tiempo, para develar sus deficiencias. $Y$ aunque el tema de su formación es omisión lamentable de la Ley 30/92 de Educación Superior -en cambio la Ley 115 reserva un capítulo a ellael debate sobre las instituciones formadoras, la calidad de los Docentes y de la enseñanza, cobran mayor relevancia durante esta década del 90.

La Ley 115 y sus decretos reglamentarios abordan reformas como la Acreditación Previa que demandan de las Facultades de Educación y Escuelas Normales Superiores una transformación en los ejes fundamentales de su formación como profesionales de la Educación, enfatizadas por la perentoriedad establecida por las normas posteriores reglamentarias. Los Decretos 709 y 272 validaron la necesidad de dotar de una estructura pedagógica, epistemológica y ética conducentes a una conciencia e identidad profesionales, un conocimiento y responsabilidad en la docencia con unas relaciones inherentes entre enseñanza, investigación, institución, comunidad educativa y sociedad, como determinantes por excelencia en la formación y el desempeño profesional.

Posiblemente la identificación de unos fundamentos teóricos de la Pedagogía, como eje fundamental de la conciencia profesional, la praxis pedagógica, apoye decididamente el cambio en los modelos curriculares impuestos a las Facultades de Educación y 
de la mentalidad hasta ahora puramente tecnologicista de muchos de los formadores de docentes. El cambio epistemológico en el proceso de conocimiento implica el reconocimiento del otro en una situación de independencia, de participación y autorreflexión permanentes, y es esencial, en esta prospectiva de cambios.

El Sistema de Formación de Docentes emerge como uno de los aparatos viables, capaz de integrar iniciativas y superar vacíos estructurales. Como medio coercitivo, por qué no, de inducir a la producción de renovaciones, de aportes al quehacer educativo permanentes, teniendo en cuenta siempre, dentro de propósitos y tareas, la evaluación permanente de las Facultades de Educación, sus currículos, la formación y el desempeño docentes.

Con Sistema o no, la Profesión Docente demanda del Sistema Educativo Colombiano el apoyo a un status profesional, el reconocimiento social y el estímulo positivo para que tanto en el proceso de formación como en el ejercicio de la actividad docente, se disponga de condiciones sociales, económicas, laborales equitativas y dignas y solidaridad para con la vida académica y profesoral.

Nada fácil, la formación de Edu. cadores no sólo necesita la presión y/o coacción externa de los cánones jurídicos. Requiere de un alto grado de conciencia de la sociedad y de los mismos educadores sobre la naturaleza de su profesión y de su desempeño, de una sólida preparación pedagógica. Del reconocimiento de la pedagogía como una ciencia y no en la pobre función de instrumento tecnológico. De la convicción de que el Maestro no es parte de esa instrumentación tecnológica sino un sujeto con autonomía y capacidad creadora y transformadora. Del convencimiento de los poderes y fuerzas intervinientes, de la sociedad $y$ de los medios de información del papel determinante del conocimiento, del liderazgo de la Escuela en el uso y transformación de este, de su protagonismo de la mano de sus Educadores para enfrentar y solventar las enormes y aceleradísimas transformaciones que están aconteciendo en un mundo igualmente cambiante, aceleradamente competitivo. Pero, además, un mundo donde sólo una sólida competencia moral puede mediar para equilibrar el trato entre los hombres y garantizar para todos la dignidad humana, la justicia, la libertad y la democracia. $Y$ ante el peligro de las hegemonías y los autoritarismos, como los de la globalización de un pensamiento único, el derecho a la crítica, al disentimiento, a la diversidad creadora.

\section{BIBLIOGRAFÍA}

CONSEJO NACIONAL DE ACREDITACIÓN, C.N.A. Criterios y procedimientos para la Acreditación Previa de los Programas Académicos de pregrado y de especialización en educación. Santafé de Bogotá: Corcas, 1998.

CONSTITUCIÓN POLITICA DE COLOMBIA. Bogotá: Temis, 1991.
Helg, Aline. La Educación en Colombia 1918-1957. Santafé de Bogotá: CEREC, 1997.

CONGRESO DE LA REPÚBLICA, Ley 30 de 1992. Santafé de Bogotá: Grupo Editorial Leyer, 1997.

LiBreros, Daniel. Políticas Educativas en Formación de Docentes. Bogotá: Universidad Pedagógica, sin publicar: 1998.

MINISTERIO DE EDUCACIÓN NACIONAL. Ley General de Educación. Santafé de Bogotá: Fecode, 1994.

Decreto 1860. Santafé de Bogotá: Serie Pedagogía y Currículo, 1994.

Decreto 709. Santafé de Bogotá: Código de la Educación y Estatuto Laboral de los Docentes, 1997.

Bogotá: Diario Oficial, 1997.

Decreto 272. Santafé de

Bogotá. Diario Oficial, 1998.

- Plan Decenal. Santafé de Bogotá: MEN, 1996.

Hacia un Sistema de Formación de Docentes, . Santafé de Bogotá: Enlace Editores, 1998.

MISIÓN DE CIENCIA, EDUCACIÓN Y DESARROLLO. Colombia al filo de la oportunidad en: Consigna publicaciones. Santafé de Bogotá: Fundación Universitaria del Área Andina, 1994. 


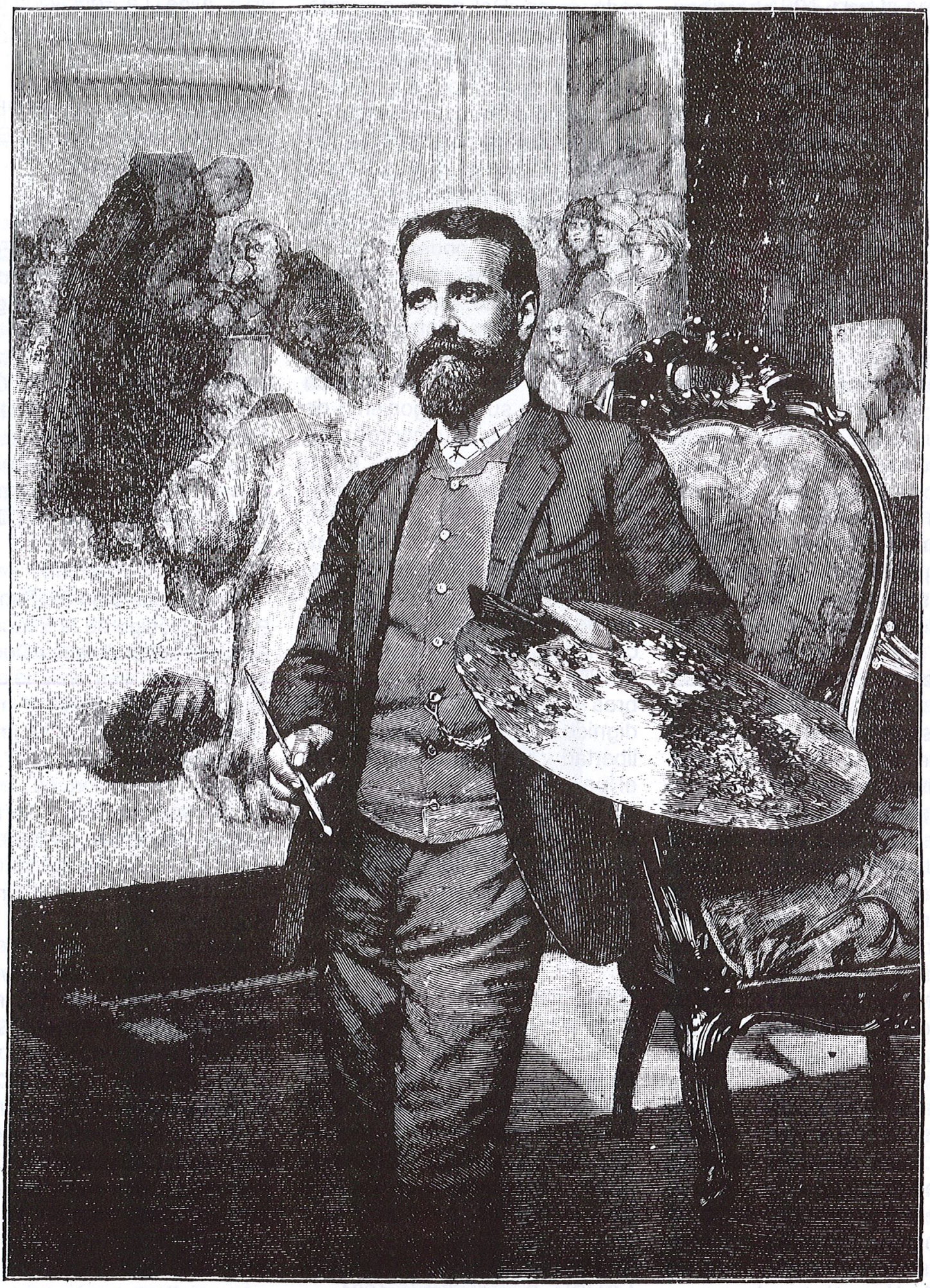

